\title{
LEI GERAL DA COPA: A EXPRESSÃO DO DIREITO PENAL ENQUANTO MECANISMO DE MANUTENÇÃO DO STATUS QUO
}

\author{
General law of the world cup: the expression of criminal law as \\ mechanism of mantainig the status quo
}

\section{Paulo César Corrêa Borges}

ProfessorAssistente-doutordaUnesp,CoordenadordoPPGDIREITO/UNESP/FRANCAe Coordenador do NETPDH - Núcleo de Estudos da Tutela Penal e Educação em DDHH. E-mail: pauloborges@franca.unesp.br.

\section{Olívia Felippe FogaÇa}

Pesquisadora - I.C. - Bolsista CNPq; bacharelanda em Direito pela Unesp; membro do NETPDH - Núcleo de Estudos da Tutela Penal e Educação em Direitos Humanos. E-mail:fogacaolivia@gmail.com.

\section{Resumo}

A Copa do Mundo é um evento de muita celebração, em especial para o Brasil, o "país do futebol". Neste ano de 2014, os brasileiros terão a grandiosa oportunidade de sediar o Mundial, oportunidade essa que abre espaço para reformas urbanas, investimentos estrangeiros, enfim, uma melhoria na condição de vida do cidadão. Por outro lado, uma reflexão mais cuidadosa faz insurgir sérios problemas enfrentados pelo país e que são agravados com a vinda do evento. A aprovação da Lei $n^{0} 12.663 / 12$, a Lei Geral da Copa, significa uma afronta direta a princípios constitucionais, recorrendo ao direito penal através da criação de crimes de caráter temporário em prol dos interesses da FIFA, entidade organizadora do evento. Traçando um paralelo com a Copa do Mundo de 2010, sediada pela África do Sul, o que se observa é uma transgressão em mesma medida, transgressão essa que se mostra ausente nos demais países-sede dos últimos vinte anos, os quais, por sua vez, tem em comum a situação de países desenvolvidos. Nesse sentido, tal reflexão faz indagar acerca da relação entre o poder econômico em jogo e a função que o direito penal acaba exercendo. 
Palavras-cheve: Direito penal. Leis penais temporárias. Lei Geral da Copa. Copa DO MUNDO.

\begin{abstract}
The World Cup is an event of great celebration, especially for Brazil, the "soccer country". In this year of 2014, Brazilians will have the great opportunity to host the World Cup, this opportunity that opens space for urban reforms, foreign investment, ultimately, an improvement in the living conditions of citizens. On the other side, a more careful reflection brings to surface serious problems the country faces and that are exacerbated by the coming event. The approval of the Law $n^{\circ} 12.663 / 12$, the General Law of the World Cup, means a direct affront to constitutional principles, resorting to criminal law by creating temporary crimes in the interests of FIFA, the organizer of the event. Drawing a parallel with the World Cup 2010 hosted by South Africa, what is observed is a transgression in equal measure, a transgression that shows absent in other host countries in the last twenty years, which in turn, have in common the situation of developed countries . Thereafter, this reflection makes one inquire about the relationship between economic power in question and the roll that criminal law plays.
\end{abstract}

Keywords: Criminal law. Temporary criminal legislation. General Law of The WORLD CUP. WORLD CUP.

SUMÁRIO: Introdução. 1. As copas do mundo e as exigências da Fifa. 2. Copa do mundo de 2014 - as concessões brasileiras à Fifa. 3. Leis Penais Temporárias e a Constituição Federal. 4. A ordem econômica e o direito penal. 5. A copa do mundo nos países subdesenvolvidos. Conclusão. Referências.

\title{
INTRODUÇÃo
}

Para os brasileiros, o presente ano promete uma agenda movimentada. Desde a memória de 50 anos de golpe militar à eleição presidencial, o ano de 2014 conta com eventos de extrema relevância. E, na seara cultural, o Brasil e o mundo terão seus olhos voltados aos estádios de futebol, que sediarão a Copa do Mundo.

$\mathrm{E}$, este evento, que leva consigo a marca registrada do povo brasileiro, é tão prestigiado que vem mobilizando nos últimos anos diversos setores da sociedade brasileira para sua realização, inclusive promovendo a premiação de jogadores das seleções brasileiras campeãs nas copas anteriores. 
No âmbito jurídico, dois projetos de lei foram propostos em 2011, dispondo sobre diversas medidas relativas à Copa de 2014, tendo um sido aprovado em 2012, e o outro em vias de ser aprovado. Já, no plano econômico, o evento prevê um incremento significativo no PIB brasileiro, principalmente por meio do turismo. Não se olvide, ainda, o legado deixado pelas inúmeras obras, desde os mais modernos estádios até a construção de linhas de trem e de aeroportos.

Um olhar mais atento para o assunto, entretanto, faz emergir reflexões que contam uma história diferente. De início, tem-se que o povo brasileiro, grande responsável pela cultura do futebol, ficará de fora, haja vista o exorbitante valor cobrado pelos ingressos.

Ademais, há que se ter cautela na interpretação do aumento do produto interno bruto (PIB), que, principalmente em um país como o Brasil, com índices elevadíssimos de desigualdade social e concentração de renda, não pode ser diretamente relacionado com o aumento dos índices de medição de qualidade social, a exemplo do índice de desenvolvimento humano (IDH).

Por fim, o tão referido legado é alvo de fundadas críticas, que, através de dados empíricos, revelam o reduzido valor social em que foram revertidos legados da Copa do Mundo de 2010, na África do Sul, bem como das Olimpíadas de Pequim em 2008, e até mesmo dos Jogos Pan-Americanos de 2007, que ocorreram no Rio de Janeiro. Os estádios, que ganharam o apelido de "elefantes brancos" pela pouca utilidade somada aos dispêndios para a manutenção, são o símbolo do dinheiro escoado pelo ralo.

O que se pretende aqui é traçar a relação da Copa de 2014 com o interesse econômico, cujas gigantes engrenagens são postas em furioso movimento, mas cujos efeitos sociais permanecem ocultos. Ocorre que esse fenômeno não atravessa a sociedade deixando os direitos ditos fundamentais incólumes. Inclusive, os arranjos feitos para a realização do evento se utilizam do direito - conforme citado anteriormente, através dos projetos de lei - para se revestirem de legalidade, muito embora permaneçam à margem da legitimidade constitucional.

Referimo-nos aos tipos penais previstos em ambos o Projeto de Lei do Senado (PLS) $n^{\circ}$ 728/11 (SENADO FEDERAL, 2011, online) e a Lei $n^{0}$ 12.663/12 (BRASIL, 2012, online) tipos penais esses que são de vigência temporária, isto é, que tem no próprio texto da lei o prazo de sua vigência, e que pretendem proteger os direitos de exploração econômica da Federação Internacional de Futebol (FIFA) e de suas empresas patrocinadoras, bem como proteger a integridade física e mental dos torcedores, dentre outras medidas.

Observando a função que essa regulamentação exerce, é possível concluir que o direito penal tem se prestado aos interesses econômicos da grandiosa FIFA, e de seus patrocinadores, os quais, por meio da Lei $n^{0} 12.663 / 12$, mais conhecida como Lei Geral da Copa, são objeto das mais variadas regalias financeiras e proteções jurídicas, reforçadas pelo PLS n ${ }^{\circ}$ 728/11. Há aqui uma verdadeira inversão de 
valores e prioridades sociais, em que o governo prejudica sua soberania em prol dos interesses econômicos.

Ampliando-se a área de análise para o plano mundial, o que se verifica é que a história se repete: em 2010, a África do Sul, país igualmente classificado como subdesenvolvido, para sediar a Copa do Mundo, atendeu a todos os mandados da FIFA, cometendo atrocidades jurídico-penais para tanto. Já, em 2006, a história é um pouco diferente, dado que a Alemanha, país-sede da referida Copa do Mundo, enfrentou algumas exigências da Federação, muito embora tenha se curvado à maioria delas pelo próprio interesse em promover a imagem do país.

Analisar de forma mais detalhada os ajustes promovidos pela FIFA no plano jurídico dos países-sede das duas últimas Copas do Mundo e desta que está por vir, especialmente no âmbito penal, e a íntima relação desses ajustes com os interesses econômicos, será o objeto de estudo da presente obra.

\section{As COPAS do MUNdo e as EXIGÊnCIAS da Fifa}

$\mathrm{Na}$ introdução ao tema deste trabalho, foram mencionadas, de forma comparativa, as Copas Mundiais de 2006 e de 2010, a primeira sediada pela Alemanha e a segunda, pela África do Sul, bem como a vindoura Copa Mundial de 2014, que ocorrerá no Brasil. Conforme citado, a FIFA, ao eleger um país candidato a sediar uma Copa do Mundo, apresenta uma extensa lista de exigências a serem cumpridas a fim de se realizar o maior campeonato de futebol do mundo.

Dentre essas exigências, há a construção ou reforma de estádios, a apresentação de uma infraestrutura urbana adequada para a recepção do evento, o registro dos mais variados símbolos oficiais da Federação e a exploração exclusiva dos lucros. Analisando a obediência dessas condições pelos países-sede das duas últimas Copas do Mundo, observa-se que há uma divergência elementar entre as posturas adotadas pela África do Sul e Alemanha.

Em reportagem publicada no site do jornal O Globo (JUPPA; DUARTE; RUETHER, 2011, online), os repórteres Fábio Juppa, Fernando Duarte e Graça Magalhães Ruether relatam que a Alemanha não cedeu às exigências de facilitação de imigração; além disso os milhares de produtores locais de cerveja se uniram em protesto diante da proibição da bebida de marcas outras que não a oficial, e venceram a batalha. Já, na África do Sul não houve qualquer resistência no tocante à política de imigração imposta pela Federação, e no âmbito jurídico, foram criadas dezenas de tribunais especiais para o processamento e julgamento célere de crimes ocorridos durante o evento.

No tocante ao pequeno comércio ou artesanato, a exploração econômica foi liberada, contanto que não houvesse qualquer utilização ilegal dos símbolos ou expressões oficiais, que englobam desde o brasão da FIFA até expressões como "Copa do Mundo" ou "África do Sul 2010", ou seja, nenhum produto que fosse interessante adquirir. 
Esse cenário instalado na África do Sul se revela condizente com a situação social do país, cujas divergências de origens étnicas e raciais são tão intensas quanto a desigualdade socioeconômica. Em um país como esse, em que as exorbitantes concentrações de renda e poder político possibilitam tomadas de decisões diametralmente opostas ao interesse social, se render às exigências da FIFA é quase natural.

A situação se agrava quando o governo sul-africano deixa de "meramente" desrespeitar as garantias constitucionais para infringi-las por meio de próprios artifícios jurídicos. Os citados tribunais especiais são censurados por muitos, e é nesse sentido que segue a opinião de Deon Bouwa, advogado sul-africano que levanta o questionamento acerca da garantia de uma defesa adequada diante de um período tão curto de tempo para o sentenciamento (apud KONCHINSKI, 2010, online). A questão, entretanto, é que aqueles são verdadeiros tribunais de exceção, nos moldes do Tribunal de Nuremberg, famoso por ter sido criado com a única finalidade de julgar os crimes cometidos por nazistas na $2^{\mathrm{a}}$ Guerra Mundial, e que ainda assim merece reprovação pela injustiça do tratamento desigual.

Mais intrigante ainda é o fato de esses tribunais especiais surgirem como imposição da FIFA somente a partir da Copa do Mundo sediada pela África do Sul. Um levantamento realizado pelo noticiário Estado de Minas revelou que nos últimos vinte anos, três foram os países europeus a sediarem a Copa do Mundo - Itália, França e Alemanha, e os demais países foram Estados Unidos, Japão e Coreia do Sul (SASSINE, online). Portanto, nos últimos 20 anos, todos os países a sediarem a Copa do Mundo foram países desenvolvidos, ou seja, países que, além de apresentarem índices sociais saudáveis, estão no comando do interesse econômico internacional, e não o contrário. Isso implica em não submeterem suas soberanias aos interesses econômicos privados, e menos ainda sacrificarem os direitos fundamentais de seus cidadãos para tanto.

A diferença da relação estabelecida entre a FIFA e países de primeiro mundo e aquela estabelecida entre a Federação e a África do Sul é abissal. No primeiro caso, existe ainda um Estado forte e em paridade de armas, preparado para negociar. Aliás, até 2010, a FIFA nem mesmo fez propostas absurdas, como a criação de tribunais especiais. Já, na África do Sul a situação é bem diversa: além de o Estado não possuir ferramentas de negociação, há também a falta de preocupação para com o interesse social somada à extrema violência, à lentidão do aparato judicial e todos os demais problemas enfrentados por um país subdesenvolvido. Nesse sentido, a FIFA acaba por exigir uma reforma drástica, ainda que temporária e com muita sujeira empurrada debaixo do tapete, para fazer o evento acontecer e ser um sucesso.

Diante dos fatos, fica claro que a intervenção da FIFA em um país-sede de uma Copa do Mundo está intimamente relacionada com a influência econômica internacional que possui o país em questão. Analisem-se, então, as peculiaridades da situação no Brasil, país eleito para sediar a vindoura Copa de 2014. 


\section{CoPA DO MUNDO DE 2014 - AS CONCESSões BRASILEIRAS À Fifa}

A história da formação do Brasil enquanto Estado em muito se assemelha à da África do Sul. Ambos foram descobertos pelos europeus em suas aventuras marítimas no final do século XV e se tornaram colônias de exploração durante mais de três séculos. Os efeitos de uma colonização predatória são cediços: conforme a história avança, a globalização estabelece relações entre todas as nações do mundo, fomentando cada vez mais o capitalismo e intensificando o desequilíbrio social e econômico entre os países.

Enquanto a riqueza sugada das colônias se concentra e circula entre os agora líderes da economia mundial, suas sociedades tentam lentamente se reerguer através da exportação de matérias primas àqueles líderes, que posteriormente vendem o produto final de volta às ex-colônias.

Atualmente, essas ex-colônias são chamadas de países "em desenvolvimento", como se se acreditasse ser esse um processo iniciado século passado, mas que tem um fim a ser atingido, quando então, ao cruzarem a linha de chegada, passarão a ser chamados de países desenvolvidos.

E, enquanto isso, em meio a todos os acontecimentos da sociedade atual, vez ou outra esses países são palco dos espetáculos promovidos pela elite capitalista e para a elite capitalista, a exemplo da Copa do Mundo de 2010 na África do Sul, e da Copa do Mundo de 2014 no Brasil.

No capítulo anterior, ficou demonstrada a assimetria entre a relação da FIFA com países desenvolvidos e com a África do Sul, e que isso se dá, em última instância, pelas condições econômicas de cada país. Vejam-se, então, as imposições da FIFA ao Brasil para a realização da Copa do Mundo de 2014 e a correspondente postura adotada pelo país.

Conforme expõe o artigo publicado no Jornal Cruzeiro do Sul, as prerrogativas da Federação se iniciam pelo direito irrestrito de exploração de suas marcas e de transmissão de som e imagem, sob pena de multa ou detenção (ALMEIDA NETO, online). Inclusive, explica o autor, a política adotada para o registro e exploração das marcas oficiais vai de encontro às previsões legais.

$\mathrm{E}$, as regalias vão ainda muito além: segundo prevê a Lei $\mathrm{n}^{\circ} 12.663 / 12$ Lei Geral da Copa, a União responderá objetivamente por quaisquer danos sofridos pela FIFA ou suas subsidiárias, responsabilidade essa apurada em processo judicial no qual a Federação será totalmente isenta de recolher custas.

Inclusive, os privilégios são tantos que a referida lei é até mesmo objeto de Ação Direta de Inconstitucionalidade proposta pelo Ministério Público (ADI 4976/ DF, 2013, online) que questiona, dentre outros tópicos, a responsabilidade civil objetiva assumida pela União, o que reforça a ideia de que o governo brasileiro não mede esforços para agradar a Federação, nem mesmo se a medida a ser tomada envolver o comprometimento direto da soberania nacional. 
Por fim, o PLS nº 728/11 propõe a criação de varas judiciais especializadas para julgar crimes relacionados ao evento e de que dispõe o texto legal, aos moldes dos já tratados tribunais especiais criados, de forma inédita, na África do Sul para a mesma finalidade.

Contudo, o aspecto mais relevante dos textos legais supramencionados, e cuja análise é objeto central deste estudo, é a constituição de novos tipos penais, em especial aqueles criados pela Lei Geral da Copa.

\section{Leis Penais Temporárias e a Constituição Federal}

A Lei Geral da Copa, conforme já descrito, previu a composição de inúmeras regalias à Federação, ainda que para isso sejam infringidas normas constitucionais, como a vedação da criação de tribunais de exceção. Embora sejam esses pontos férteis de discussão, o objeto do presente trabalho são os crimes criados pela referida lei.

A Lei $n^{\circ} 12.663 / 12$, em seu Capítulo VIII, trata das disposições penais, definindo quatro tipos penais de menor potencial ofensivo, isto é, crimes cujas penas máximas não ultrapassem dois anos, e que, portanto, podem ser julgados pelos Juizados Especiais Criminais, cabendo nestes casos, quando possível, a conciliação mediante reparação civil dos danos, a transação penal e a suspensão condicional do processo.

Os elementos dos tipos, de modo geral, envolvem a utilização indevida de símbolos oficiais da FIFA, bem como a prática de marketing de emboscada, que consiste na exploração comercial através da associação com os eventos da Copa do Mundo sem a devida autorização.

Nesse sentido, pode-se extrair que o bem juridicamente tutelado por esses tipos penais são os lucros da FIFA, de forma direta, e o interesse econômico privado, de forma indireta. Em última instância, portanto, o que se tem é a utilização do sistema penal para conter os percalços da exploração econômica de um evento como a Copa do Mundo.

Em outras palavras, esses tipos penais permitem coibir, até mesmo com pena de detenção, o incremento da renda dos pequenos comerciantes, que representam uma parcela ínfima dos lucros a serem auferidos com o evento, para garantir que a totalidade desses lucros se concentre nas mãos da Federação.

A situação se torna mais perversa quando se analisa a temporalidade da legislação. Conforme dito na introdução deste trabalho, a Lei Geral da Copa é uma lei temporária, e seus tipos penais devem viger até 31 de dezembro de 2014. Isso implica em que, uma vez finda a Copa do Mundo, aqueles crimes deixam de existir, muito embora os fatos possam continuar sendo processados e julgados, e seus autores possam cumprir suas penas integralmente, enquanto o presidente da FIFA e seus membros seguem suas vidas. 
Essa circunstância está prevista no art. $3^{\circ}$ do Código Penal (BRASIL, 1984, online), que diz: “A lei excepcional ou temporária, embora decorrido o período de sua duração ou cessadas as circunstâncias que a determinaram, aplica-se ao fato praticado durante sua vigência." Isso significa que as leis temporárias são ultrativas, isto é, tem aplicação para além de sua existência.

A grande questão é que, no entendimento de alguns penalistas, as leis temporárias, instituto presente no Código Penal (CP) que data de 1940, não foram recepcionadas pela Constituição Federal (CF) de 1988. Com efeito, diz o art. 5º XL, da Carta Magna, que "[...] a lei penal não retroagirá, salvo para beneficiar o réu." (BRASIL, 1988, online).

O fenômeno da retroatividade ocorre em situações de transição entre duas normas, em que uma, por motivo de incompatibilidade, revoga a anterior, e atinge fatos anteriores a ela caso beneficie a situação do réu perante a lei anterior. $\mathrm{O}$ que determina o art. $5^{\circ}, \mathrm{XL}$, é que a lei penal nunca deve atingir fatos anteriores a sua criação, exceto quando beneficiar o réu.

Ocorre que a lei temporária não se enquadra na situação de transação entre duas normas, visto que é uma lei criada para viger durante um tempo previamente fixado, e que se autorrevogará quando atingir esse prazo. No entanto, e por determinação do art. $3^{\circ}$ do $\mathrm{CP}$, essa lei continuará surtindo efeito após sua autorrevogação, isto é, será ultrativa.

E qual é a relação, então, entre a retroatividade de que trata a Constituição Federal e a ultratividade a que se refere o Código Penal? Oras, a regra constitucional é clara ao dizer que a lei penal somente deve retroagir para beneficiar o réu, sem qualquer condição. Nesse sentido, a interpretação correta dessa norma constitucional é a de que a lei penal deve sempre retroagir se beneficiar o réu.

Posto isso, analisem-se as leis temporárias: por sua natureza, elas são criadas para enrijecer o sistema penal em uma situação transitória de emergência (PRADO, 2010, p. 199). Desse modo, quando uma lei temporária se autorrevoga, a situação de normalidade, juntamente com o ordenamento jurídico pré-existente - que é mais benéfico do que a situação transitória de emergência, se restabelecem, de modo que deveriam retroagir para beneficiar o réu.

Essa retroatividade, todavia, não ocorre, por força do art. $3^{\circ}$, que determina a ultratividade das leis temporárias. Estabelece-se, assim, um embate direto entre norma constitucional e infraconstitucional, que poderia ser facilmente solucionado por meio das regras de hermenêutica, que, no caso em tela, identificam uma situação de não recepção do $\operatorname{art.} 3^{\circ}, \mathrm{CP}$, pela $\mathrm{CF} / 88$.

É esse o posicionamento de Zaffaroni e Pierangeli (2006, p. 200), que entendem ser duvidosa a constitucionalidade do art. $3^{\circ}, \mathrm{CP}$, "[...] posto que constitui exceção à irretroatividade legal que consagra a Constituição Federal ('salvo para beneficiar o réu') e não admite exceções, ou seja, possui caráter absoluto."

$\mathrm{O}$ assunto, contudo, não é pacífico. E, o argumento que parece prevalecer 
é o de que se utiliza Paulo de Souza Queiroz (2001, p. 77): “[...] se tais normas, ao final de sua duração, perdessem, sem mais, o seu poder coercitivo quanto aos fatos consumados durante a sua vigência, simplesmente ninguém as respeitaria, seriam de todo inúteis [...]."

Tal fundamento, entretanto, não procede, pois, caso contrário, bastaria invocar a necessidade de se garantir o poder coercitivo de uma norma para um passe livre em direção à inconstitucionalidade.

Ocorre que essa discussão jamais deixou o plano doutrinário, de modo que, na prática, as leis temporárias acabam sendo de fato ultrativas. E, para além da discussão acerca da constitucionalidade ou não dos efeitos ultrativos das leis temporárias, as principais implicações que apresenta esse instituto são de ordem social.

Com efeito, segundo Paulo César Corrêa Borges (2005, p. 131), as leis temporárias tem, em verdade, uma natureza ditatorial ou antidemocrática, "[...] que afrontam a estabilidade das relações jurídicas e são circunstanciais", representando, assim, riscos constantes ao modelo de Estado Democrático de Direito.

$\mathrm{E}$, conforme se amplie o foco de análise, é possível perceber que essa ameaça ao Estado Democrático de Direito se apresenta a todo o momento, por todos os aspectos do sistema penal brasileiro, revelando uma sintonia entre a função do macrossistema que exerce o direito penal e aquela executada pelos microssistemas, como o instituto das leis temporárias.

A função a que se presta a Lei Geral da Copa, como já visto neste capítulo, é garantir que todos os interesses econômicos da FIFA possam ser atendidos em nível máximo de eficácia. Analise-se, agora, o papel que tem cumprido o direito penal brasileiro como um todo.

\section{A ordem econômica e o direito Penal}

O sistema penal brasileiro é atualmente reconhecido por ser uma gigante máquina transgressora dos direitos humanos. Desde a lentidão dos órgãos judiciais, que prolonga em demasia os processos criminais e assim, muitas vezes, a privação da liberdade, até o fracasso do sistema carcerário, marcado pela superlotação, condições degradantes de infraestrutura e higiene, o direito penal incide transgredindo os mais diversos direitos fundamentais protegidos pela Carta Magna. Até mesmo sua atuação legítima, que consiste na aplicação de pena privativa de liberdade, implica em transgredir a liberdade de ir e vir.

Esse estado de coisas, que, num primeiro momento, parece caótico e insustentável, se perpetua sem previsão de mudanças graças à estrutura política, que concentra o poder de manutenção do status quo no topo da pirâmide hierárquica das classes sociais. Com efeito, a perversidade do sistema penal brasileiro somente permanece porque há uma seleção cuidadosa de seus indivíduos-alvo.

De fato, a maioria esmagadora da população carcerária é composta por 
homens jovens, negros e pobres; um conjunto característico tão constante que remete à ideia de um depósito de indesejáveis. Essa uniformidade entre os membros que compõem a população carcerária é explicada pela teoria do etiquetamento, ou labbeling approach, estudada pelo sociólogo Alessandro Baratta (2002). Em linhas gerais, “[...] sob a etiqueta de 'delito', agrupa-se toda uma série de comportamentos que nada têm em comum, exceto quanto ao fato de estarem criminalizados. Significa, ainda, que o crime não é um objeto do sistema penal, senão resultado mesmo do seu funcionamento." (QUEIROZ, 2001, p. 61).

Nesse sentido, a teoria do etiquetamento explica esse fenômeno de criminalização de um estereótipo, pouco importando a nocividade deste ou daquele comportamento para a sociedade. Em verdade, o direito penal acaba por ser "[...] um instrumento de produção e de reprodução da desigualdade na sociedade capitalista, cuja função é assegurar a verticalidade da escala social e as "relações de subordinação e exploração do homem pelo homem'.” (BORGES; MACHADO, 2012, p. 96).

$\mathrm{E}$, a incidência da teoria do etiquetamento no sistema penal brasileiro é facilmente verificada: “[...] em relação aos menos favorecidos socialmente, aplica-se o Direito Penal segundo o dura lex sed lex, mas com parcimônia quando o delinqüente pertence às classes sociais mais altas." (BORGES, 2005, p. 75).

Em países como o Brasil, em que o direto penal é utilizado como ferramenta de contenção das classes sociais mais baixas, além de ser instrumento para atingir interesses econômicos das classes sociais mais altas, o que se verifica é a busca pelo direito penal como prima ratio, ou seja, como solução primária para os problemas socioeconômicos. Ademais, existe uma relação direta entre essa estratégia e o fracasso dos órgãos repressores, de modo que essas nações tendem a apresentar altos índices de criminalidade.

Em sentido oposto, países em que há um menor índice de desigualdade social, e que, portanto, não necessitam recorrer ao direito penal como ferramenta de contenção das classes sociais mais desfavorecidas, os órgãos repressores revelam-se bem-sucedidos, e seus índices de criminalidade são baixos.

Para melhor compreensão, segue abaixo uma tabela com os índices de segurança pessoal e desigualdade social dos seguintes países: Japão, Alemanha, Itália, Brasil e África do Sul. O índice de segurança pessoal é inversamente proporcional à criminalidade, de modo que países com maior índice de segurança pessoal tem menor criminalidade.

Quadro 1 - Relação entre a distribuição de renda e a violência

\begin{tabular}{|c|c|c|}
\hline & Índice de Segurança Pessoal & $\begin{array}{l}\text { Índice de } \\
\text { Desigualdade } \\
\text { Social }\end{array}$ \\
\hline Japão & 92.33 & - \\
\hline Alemanha & 88.19 & 28.3 \\
\hline
\end{tabular}




\begin{tabular}{|c|c|c|}
\hline Itália & 67.83 & 36.0 \\
\hline Brasil & 37.50 & 54.7 \\
\hline África do Sul & 30.90 & 63.1 \\
\hline
\end{tabular}

Fonte: Social Progress Imperative (2014, online); Programa das Nações Unidas para o desenvolvimento (2013, online).

Já, o índice de desigualdade social, extraído do Relatório do Desenvolvimento Humano 2013 elaborado pela Organização das Nações Unidas (ONU), é calculado através do coeficiente Gini, que mensura a distribuição de renda, o mesmo utilizado pela organização (PROGRAMA DAS NAÇÕES UNIDAS PARA O DESENVOLVIMENTO, 2013, pp. 158 - 161).

Interpretando os dados da tabela, verifica-se uma constante: Japão, Alemanha e Itália, que são países desenvolvidos, apresentam um alto nível de segurança pessoal, o que implica em um baixo nível de criminalidade. E, esses mesmos países são os que apresentam os mais baixos níveis de desigualdade de distribuição de renda, com exceção do Japão, cujo índice não é indicado pela ONU, muito embora seja um país com uma das melhores distribuições de renda do mundo.

E, para o Brasil e África do Sul, países subdesenvolvidos, a conclusão é condizente: ambos apresentam os menores níveis de segurança pessoal, traduzindose em maiores níveis de criminalidade, e são os que apresentam os maiores níveis de desigualdade de distribuição de renda.

Assim, os dados ora apresentados permitem concluir que há uma relação direta entre a desigualdade social e a criminalidade. Além disso, países que se enquadram em situações crônicas de desigualdade social tendem a recorrer ao direito penal para solucionar problemas socioeconômicos, ao estilo da teoria do etiquetamento. Estudem-se agora os impactos dessa situação em um evento, a princípio desvinculado dos mais profundos problemas sociais enfrentados por países subdesenvolvidos, como é o caso da Copa do Mundo.

\section{A COPA DO MUNDO NOS PAÍ́SES SUBDESENVOLVIDOS}

Os países que integram a tabela do capítulo anterior não foram escolhidos de forma aleatória. Notadamente, todos são países que sediaram a Copa do Mundo nos últimos 20 anos, com exceção do Brasil que deve sediá-la neste ano de 2014.

Além disso, os resultados extraídos das informações ali contidas apresentam uma linearidade curiosa com os eventos promovidos pela FIFA: aqueles países ditos desenvolvidos, e que ocupam as três primeiras posições na tabela - Japão, Alemanha e Itália, ao sediarem as respectivas Copas do Mundo, não recorreram à criação de leis temporárias com previsão de tipos penais a fim de corresponder aos interesses econômicos da FIFA, bem como de conter os comportamentos economicamente indesejáveis de seus povos. 
Inclusive, a Alemanha, em 2006, até mesmo enfrentou e venceu disputas acerca de algumas exigências da FIFA, impondo sua soberania perante uma das entidades privadas mais fortes e influentes do mundo (vide segundo capítulo - As copas do mundo e as exigências da FIFA).

Diversa é a situação da África do Sul e do Brasil - países subdesenvolvidos que ocupam a base da tabela. São os primeiros países subdesenvolvidos a sediar a Copa nos últimos vinte anos, e os primeiros dispostos a criar leis temporárias conflitantes com suas Constituições, prevendo tribunais "especiais" para o julgamento de crimes especificamente criados para garantir o sucesso do evento.

Ambos são países que põe em xeque suas soberanias para atender as exigências econômicas da FIFA, recorrendo ao direito penal em crise como meio de mostrar trabalho feito ao mesmo tempo em que contorna os problemas sociais típicos do subdesenvolvimento.

$\mathrm{Na}$ África do Sul, o abandono das diretrizes constitucionais beira o absurdo, como é o caso de um jovem de 22 anos, que, ao ser processado por um tribunal "especial", foi sentenciado a 5 anos de pena privativa de liberdade pelo crime de roubo simples, sanção muito mais severa do que o previsto na legislação ordinária do país, tudo em virtude de a vítima ser um turista (MARTINS, online).

Já, no caso do Brasil, o que se observa é uma impropriedade abusiva no uso do direito penal, dado que a Lei Geral da Copa dispõe sobre infrações de menor potencial ofensivo, que em grande parte podem ser substituídos por multa, havendo assim um abandono completo da ideia do direito penal como ultima ratio, ideia essa preconizada implicitamente pela Constituição Federal, que adota o princípio da intervenção mínima do direito penal (BORGES, 2005, p. 70-72).

Com efeito, muito embora, ao final, a pena de multa acabe agredindo a liberdade de ir e vir na mesma medida que uma sanção administrativa, as consequências são bem mais severas. $\mathrm{O}$ indivíduo condenado deixa de ser um réu primário, nisso acarretando diversos outros benefícios dos mais variados âmbitos do direito.

Resta demonstrada, assim, a estreita relação entre o poder econômico e o desrespeito aos princípios constitucionais e até mesmo à soberania de uma nação, por meio do direito penal, ora exemplificada pelas experiências vivenciadas por Brasil e África do Sul enquanto países-sede da Copa do Mundo.

\section{Conclusão}

O Brasil encontra-se a poucas semanas de recepcionar o maior campeonato mundial de futebol. A empolgação para os brasileiros é especial, haja vista a cultura do futebol cultivada no país. Por outro lado, a revolta também é grande. Pelas ruas e pela internet, é possível esbarrar em incontáveis protestos, exigindo saúde e educação no "padrão FIFA", questionando a verdadeira melhoria de vida dos cidadãos brasileiros com a vinda da Copa. 
Os vultosos valores investidos para a realização da Copa são fonte de escândalos, tamanho o desvio de dinheiro, dado que nem mesmo os estádios estão finalizados, enquanto os serviços públicos de base vão de mal a pior.

$\mathrm{Na}$ esfera jurídica, são elaborados projetos de leis temporárias com previsões penais a fim de garantir que os indesejáveis sejam contidos em seus devidos lugares. Em especial, a Lei n ${ }^{0}$ 12.663/12 - Lei Geral da Copa - cria crimes de utilização indevida de símbolos oficiais e marketing de emboscada para que os pequenos comerciantes, membros das classes baixas, não se apoderem de nenhuma parcela dos lucros.

Voltando a atenção para o passado, é possível constatar uma situação similar na áfrica do Sul em 2010, primeiro país subdesenvolvido a recepcionar o Mundial nos últimos 20 anos. Lá, também se recorreu ao enrijecimento temporário do sistema penal com o intuito de conter a atuação dos indesejáveis.

Já, em países-sede das Copas anteriores, como a Alemanha, Itália e Japão, os direitos fundamentais, que, em momentos de normalidade são violados em uma escala bem menor do que em países como o Brasil e a África do Sul, não foram fonte de violação institucionalizada por leis penais temporárias, ao estilo dos dois últimos.

A partir de um levantamento de dados, pôde-se observar, ainda, que aqueles países desenvolvidos, que não necessitaram recorrer ao sistema penal como forma de reger suas comunidades diante de grandes eventos, são os países com os menores índices de violência do mundo; enquanto Brasil e África do Sul, países com arcabouços completos de direito penal, encontram-se no topo da lista dos países mais violentos do mundo.

Da mesma forma, os países subdesenvolvidos foram os que apresentaram os maiores índices de concentração de renda do mundo, enquanto os demais países analisados apresentaram os melhores índices de distribuição da renda.

Nesse sentido, estabelece-se uma relação direta entre as condições econômicas dos membros de um dado país, a consequente violência que essas condições geram, e a intervenção do sistema penal enquanto instrumento de contenção dos indesejáveis economicamente, ao mesmo tempo em que mantém e intensifica a situação posta.

Nos países subdesenvolvidos, em que há grande concentração de renda, os índices de violência são igualmente absurdos, e seus aparelhos repressivos, apesar de fracassados, são bem completos. E, diante da criação de legislação penal temporária em ambos Brasil e África do Sul para os eventos da FIFA, constata-se a real função do sistema penal: este se presta a manter o status quo intrínseco à atual ordem econômica capitalista, seja em âmbito nacional, seja em âmbito mundial. Assim, nada mais adequado do que as manifestações diante do Mundial que está por vir: a Copa é para os ricos. 


\section{REFERÊNCIAS}

ALMEIDA NETO, Jaime Rodrigues de. Lei Geral da Copa: a Fifa, suas marcas e seus superpoderes. Jornal Cruzeiro do Sul, Sorocaba, 14 jun. 2013. Cad. A, p. 2. Disponível em: http://www.cruzeirodosul.inf.br/materia/479600/lei-geral-da-copa -a-fifa-suas-marcas-e-seus-superpoderes. Acessado em: 04.04.2014.

BARATTA, Alessandro. Criminologia crítica e crítica do direito penal: introdução à sociologia do direito penal. 3. ed. Rio de Janeiro: Revan : Instituto Carioca de Criminologia, 2002.

BORGES, Paulo César Corrêa. Direito penal democrático. São Paulo: Lemos \& Cruz, 2005.

MACHADO, Antônio Alberto. Minimalismo penal: retórica e realidade. In:_ (Org.). Leituras de um realismo jurídico-penal marginal: homenagem a Alessandro Baratta. São Paulo: NETPDH; Cultura Acadêmica Editora, 2012.

BRASIL. Lei n. 7. 209, de 11 de junho de 1984. Altera dispositivos do Decreto-Lei $\mathrm{n}^{\circ} 2.848$, de 7 de dezembro de 1940 - Código Penal, e dá outras providências. Diário Oficial da União, Brasília, DF, 13 jul. 1984. p. 1. Disponível em: http://www.planalto.gov.br/ccivil_03/LEIS/1980-1988/L7209.htm\#art1. Acessado em: 2014.

BRASIL. Constituição da República Federativa do Brasil de 1988. Diário Oficial da União, Poder Legislativo, Brasília, DF, 5 out. 1988. Seção 1. Anexo. Disponível em: http://www.planalto.gov.br/ccivil_03/constituicao/constitui\%C3\%A7ao.htm. Acesso em: 2014.

Lei n. 12.663, de 5 de junho de 2012. Dispõe sobre as medidas relativas à Copa das Confederações FIFA 2013, à Copa do Mundo FIFA 2014 e à Jornada Mundial da Juventude - 2013, que serão realizadas no Brasil; altera as Leis nㅡㅗ 6.815 , de 19 de agosto de 1980, e 10.671, de 15 de maio de 2003; e estabelece concessão de prêmio e de auxílio especial mensal aos jogadores das seleções campeãs do mundo em 1958, 1962 e 1970. Diário Oficial da União, Poder Executivo, Brasília, DF, 5 jun. 2012. p. 3. Disponível em: http://www.planalto.gov.br/ccivil_03/_Ato20112014/2012/Lei/L12663.htm. Acessado em: 2014.

Supremo Tribunal Federal: processos: acompanhamento processual.

Disponível em: http://www.stf.jus.br/portal/processo/verProcessoAndamento.asp? numero $=4976 \&$ classe $=$ ADI $\&$ codigoClasse $=0$ \&origem $=J U R \&$ recurso $=0 \&$ tipoJulgamento=M. Acessado em: 2014.

JUPPA, Fábio; DUARTE, Fernando; RUETHER, Graça Magalhães. Anfitriões da copa do mundo bem diferentes no caminho da Fifa. O Globo, Rio de Janeiro, 22 out. 2011. Disponível em: http://oglobo.globo.com/esportes/copa2014/mat/2011/10/22/ 
anfitrioes-da-copa-do-mundo-bem-diferentes-no-caminho-da-fifa-925636503.asp. Acessado em: 03.04.2014.

KONCHINSKI, Vinicius. Copa muda trâmite de processos criminais na África do Sul. Agência Brasil, Brasília, DF, 22 jun. 2010. Disponível em: http://memoria.ebc. com.br/agenciabrasil/noticia/2010-06-22/copa-muda-tramite-de-processos-criminais-na-africa-do-sul. Acessado em: 28.04.2014.

MARTINS, Antonio. Copa-2014: Brasil terá tribunais de exceção? Carta Capital, São Paulo, 5 dez. 2013. Disponível em: http://www.cartacapital.com.br/blogs/outras-palavras/copa-2014-brasil-tera-tribunais-de-excecao-7783.html. Acessado em: 20.04.2014.

PRADO, Luiz Regis. Curso de direito penal brasileiro: parte geral, arts. $1^{\circ}$ a 120 . 10. ed. rev., atual. e ampl. São Paulo: Ed. Revista dos Tribunais, 2010. v. 1.

PROGRAMA DAS NAÇÕES UNIDAS PARA O DESENVOLVIMENTO. Relatório do desenvolvimento humano 2013. Disponível em: http://www.un.cv/files/ HDR2013\%20Report\%20Portuguese.pdf. Acessado em: 19.04.2014.

QUEIROZ, Paulo de Souza. Direito penal: introdução crítica. São Paulo: Saraiva, 2001.

SASSINE, Vinícius. Fifa impôs tribunal só a africanos. Estado de Minas, Belo Horizonte, 12 out. 2011. Disponível em: http:/www.em.com.br/app/noticia/politica/2011/10/12/interna_politica,255485/fifa-impos-tribunal-so-a-africanos.shtml. Acessado em: 03.04.2014.

SENADO FEDERAL. Projeto de lei n. 728, de 9 de dezembro de 2011. Define crimes e infrações administrativas com vistas a incrementar a segurança da Copa das Confederações FIFA de 2013 e da Copa do Mundo de Futebol de 2014, além de prever o incidente de celeridade processual e medidas cautelares específicas, bem como disciplinar o direito de greve no período que antecede e durante a realização dos eventos, entre outras providências. Diário do Senado Federal, Brasília, DF, 10 dez. 2011. pp. 53153-53165. Disponível em: http://legis.senado.leg.br/mateweb/arquivos/mate-pdf/100792.pdf. Acessado em: 2014.

SOCIAL PROGRESS IMPERATIVE. Social Progress Index 2014. Disponível em: http://www.socialprogressimperative.org/data/spi\#data_table/countries/com4/ $\operatorname{dim} 1, \operatorname{com} 4, \operatorname{dim} 2, \operatorname{dim} 3$. Acessado em: 19.04.2014.

ZAFFARONI, Eugênio Raúl; PIERANGELI, José Henrique. Manual de direito penal brasileiro: parte geral. 6. ed. rev. e atual. São Paulo: Ed. Revista dos Tribunais, 2006. 